\title{
Allocating time to future tasks: The effect of task segmentation on planning fallacy bias
}

\author{
DARRYL K. ForSYTH \\ Massey University, Auckland, New Zealand \\ AND \\ Christopher D. B. BurT \\ University of Canterbury, Christchurch, New Zealand
}

\begin{abstract}
The scheduling component of the time management process was used as a "paradigm" to investigate the allocation of time to future tasks. In three experiments, we compared task time allocation for a single task with the summed time allocations given for each subtask that made up the single task. In all three, we found that allocated time for a single task was significantly smaller than the summed time allocated to the individual subtasks. We refer to this as the segmentation effect. In Experiment 3, we asked participants to give estimates by placing a mark on a time line, and found that giving time allocations in the form of rounded close approximations probably does not account for the segmentation effect. We discuss the results in relation to the basic processes used to allocate time to future tasks and the means by which planning fallacy bias might be reduced.
\end{abstract}

Every day, individuals make estimates of the "time required" for future tasks. Two research literatures address this type of estimation process. The time-management literature considers the allocation of time to future tasks within the broader framework of planning and prioritizing tasks (see Claessens, Van Eerde, Rutte, \& Roe, 2004, for a review, and Macan, 1994). In contrast, there is a literature focusing specifically on temporal aspects of memory that has tended to consider only duration-estimation processes (see Block \& Zakay, 1997; Roy, Christenfeld, \& McKenzie, 2005, for recent reviews). A common finding in many experiments on time estimation is that estimation is related to the actual duration of the target stimuli with the duration of short stimuli typically being overestimated, whereas for longer stimuli the result is often underestimation. The objective of the present research was to examine these effects within a time-management framework, with the possibility that the time allocated to a task would change if the target event (project) were divided into subtasks prior to time allocations. Many small tasks are often required for the completion of a project. Time can be allocated to these individually (multiple short tasks) or in relation to the entire group of tasks that make up the project. This research investigated whether a single time allocation given for a group of tasks differs significantly from the sum of the time allocations for the subtasks.

To develop specific predictions for the research, it is necessary to consider several issues. We briefly note each, and then explore them in detail. First, we examine research on duration estimation trends that has shown that estimation is related to the size of the target task. Second, a key feature of time management is the division of projects into subtasks, the prioritization of these, and the allocation of time to each. Thus, there is an inherent task size reduction aspect to time management. A third issue is the use of rounded close approximations when making time allocations, and we discuss how this response tendency may produce different time allocations under different task-size conditions. As noted above, many experiments on time estimation have found that the duration of short stimuli is typically overestimated, whereas that of longer stimuli is often underestimated. Eisler (1976) reviewed a large body of laboratory studies that found evidence of this type of response tendency for very short laboratorygenerated stimuli. Research on task and project planning (e.g., Buehler, Griffin, \& MacDonald, 1997; Buehler, Griffin, \& Ross, 1994; Byram, 1997; Newby-Clark, Ross, Buehler, Koehler, \& Griffin, 2000) has also found that estimated duration is related to actual task duration, with short tasks being overestimated and longer tasks being underestimated. This underestimation has been labeled the planning fallacy bias (Kahneman \& Tversky, 1979), and it can lead to unwanted consequences such as failing to complete tasks. Obviously, it would be useful if a process could be found that reduced the possibility of planning fallacy bias. One aspect of time management that appears not to have been considered by research on the planning fallacy is the principle of task segmentation.

Much of the literature on time management, and several models of the time management process (e.g., Claessens et al., 2004; Macan, 1994), suggest that whatever is being managed/scheduled should be divided into component parts

C. D. B. Burt, christopher.burt@canterbury.ac.nz 
and that these parts should be prioritized and allocated time. Furthermore, products provided for time management, such as planners and diaries, typically offer relatively short intervals into which tasks can be scheduled (Burt \& Forsyth, 1999), a design consistent with the principle of dividing a project into subtasks and allocating time to each. The division of a project into subcomponents undoubtedly has advantages with respect to task clarity and resource (other than time) allocation. Furthermore, task segmentation may reduce the possibility of planning fallacy bias, because the duration of short tasks is more likely to be overestimated. That is, the summed time allocation for a project's subtasks may show less evidence of planning fallacy bias than a single time allocation for the entire task might.

The issue of time allocations for an entire project versus for a project's subtasks has been explored within the domain of software development (see Grimstad, Jørgensen, \& Moløkken-Østvold, 2006, for a review of software effort-estimation research). Jørgensen (2004) contrasted top-down versus bottom-up "effort allocations." Top-down required a single effort allocation (made in work hours) for an entire software development project, whereas bottom-up required the work to be divided into activities and the effort for each of these to be estimated. Two softwaredevelopment projects that varied substantially in actual time (one required $1,340 \mathrm{~h}$, the other $766 \mathrm{~h}$ ) were used, and seven teams made effort allocations for each, under either top-down or bottom-up instructions. Unfortunately, no statistical tests were applied to the data; but from the condition means reported and the range of over- and underestimations (four bottom-up based and six top-down based estimates were overestimates), no clear evidence suggesting a significant effect of allocation strategy was found. Jørgensen did not report the size of the subtasks that were allocated time in the bottom-up condition, but from the actual project durations reported, they were probably still substantial (long) tasks. Furthermore, the effort (time) allocations were made by teams, rather than by individuals.

Research on unpacking, where the subcomponents of a task are listed specifically before time allocation (e.g., Kruger \& Evans, 2004), has used much shorter tasks that are perhaps more typical of everyday life (e.g., preparing for a date, formatting a document, cooking a meal), and that comprise short subtasks. Under the unpacking paradigm, participants give either a single time allocation for a task without first listing its components or a single estimate after first unpacking (listing) its components. For example, in Experiment 2 of Kruger and Evans, participants estimated how long it would take them to get ready for a date. In the unpacked condition, participants first listed all of the tasks involved in getting ready before giving their estimate for the whole task; participants in the packed condition were not given this instruction and made an estimate for the whole task. Kruger and Evans showed that unpacking produced larger estimates, and, in two experiments, fewer planning fallacy bias estimates. The present research applied the time-management principle of task segmentation (unpacking), but in contrast to Kruger and Evans's procedure, participants were requested to make a time allocation for each subtask. (See Byram, 1997, Experiment 1, for a study where estimates were made for unpacked task components, although no significant effect of this was observed.) We predicted that summed subtask estimates should produce larger time allocations for the entire task than those for the entire task.

Giving estimates in rounded units or numbers is a reasonably well-established finding in estimation research and could result in different estimation outcomes under wholeand subtask estimation strategies. Burt and Kemp (1994) examined estimated and actual duration for 10 different tasks, and median estimated durations for the 10 tasks were $2,10,5,3,2.2,15,15,14,10$, and $7 \mathrm{~min}$. Thus, $50 \%$ of the tasks examined produced median estimates that were multiples of 5 (rounded). Note also that for 7 of the tasks, all of which were short-duration tasks, the median estimated duration was an overestimation. Francis-Smythe and Robertson (1999) have also discussed how "rounding" may affect task duration estimation. Likewise, Zakay (1990) noted that any verbal estimate of a duration is prone to error arising from the response bias of reporting durations in round numbers (see Hornik, 1981; Huttenlocher, Hedges, \& Bradburn, 1990; Oden, 1987; Smith \& Medin, 1981).

If an individual is faced with performing an activity that has four subtasks, and if each subtask actually takes around 4 min to complete, it is likely that rounding will lead the individual to allocate $5 \mathrm{~min}$ to each subtask, giving a total time allocation of $20 \mathrm{~min}$. If the four subtasks are allocated time as a cluster (and if one assumes the 4-min actual time per task component, for a total actual time of $16 \mathrm{~min}$ ) the nearest rounded unit is $15 \mathrm{~min}$. Thus, rounding might produce an overall time allocation of $20 \mathrm{~min}$ (an overestimation) for the target activity under the subtask time-allocation strategy, and a 15-min allocation (an underestimation) under the wholetask strategy. In Experiments 1 and 2, we looked specifically for evidence of rounding to close approximations.

In summary, Experiments 1 and 2 examined the prediction that the summed time allocations for short tasks would be significantly larger than a single allocation for the entire task set. This prediction was based on the general response tendency found in estimation research that short intervals are generally overestimated in comparison with longer intervals. Furthermore, past research suggested that participants are likely to provide estimates that are in the form of rounded close approximations (e.g., 5-min "chunks"), and we specifically examined the data to determine whether this overreliance on rounded close approximations could account for overestimations for very short tasks. In Experiment 3, the use of rounded close approximations was made more difficult by requesting participants to make time allocations for complete tasks and for subtasks by placing a mark on a timeline.

\section{EXPERIMENT 1}

\section{Method}

The experiment contained two participant conditions, both involving the allocation of time and completion of the same six officetype tasks. In Condition 1, three of the tasks were grouped together to form one set of activities to be allocated time, and the other three tasks were allocated time as separate tasks. In Condition 2, the three tasks allocated time as one set of activities in Condition 1 were al- 
located time as individual tasks, and the remaining three tasks allocated time as a task set. These manipulations resulted in both groups' providing four time allocations, three relating to individual tasks and one relating to a set of tasks.

Participants. Twenty male and 20 female students, with a mean age of 22.5 years, participated in the experiment. Participants received NZ\$20 remuneration and were debriefed after the experiment.

Materials. Time allocations were made on a plain sheet of A4 paper.

Tasks. Two criteria were used in the development of the six experimental tasks. First, a balance was sought between creating an office environment and having tasks that all participants would find at least somewhat familiar. Second, the design of individual tasks was based on previous research (e.g., Burt \& Kemp, 1994) and on an informal pilot study, so as to have relatively short average completion times of between 3 and 8 min.

Participants received the task descriptions shown in Appendix A.

Procedure. Participants were assigned randomly to one of two conditions. In the first condition, Tasks 1-3 were allocated time separately and Tasks 4-6 were grouped together and allocated time as a task set. In Condition 2, Tasks 1-3 were grouped together and allocated time as a task set, whereas Tasks 4-6 were allocated time separately.

Participants were seated individually in a cubicle that contained a table, experimental instructions, task descriptions, a time allocation sheet, folders containing task materials, a telephone and directory, and a "Completed Task" tray. Each participant was instructed to read the following instructions:

This experiment examines job satisfaction in office work. You are required to complete six tasks. These tasks can be carried out in any order you choose, however you must fully complete a task before you move on to the next. Try to imagine that you are working in an office situation and the completion of these tasks is part of your duties. Specifically you are required to: Read the accompanying sheet that describes the tasks [this sheet listed 3 tasks separately and three as a group of tasks]. Schedule the completion of the tasks by entering the order you propose to complete the tasks, along with the time you expect to need for completion of each.

Participants were not constrained to provide duration estimates in any particular scale (i.e., minutes vs. seconds). The participants then completed the tasks. A researcher discretely recorded the time taken for the participant to complete each task (note that for tasks in which the participant left the laboratory, the time during which they were away was recorded).

\section{Results and Discussion}

Table 1 shows the mean actual duration; mean, median, and modal time allocation; and mean signed error (time allocation minus actual duration) for each task. Inspection of Table 1 indicates that the mean signed errors are positive for all six tasks (when scheduled as separate tasks), meaning that participants tended to overestimate the amount of time that they actually needed in order to complete each task. Comparison of the overall actual time required to complete the experimental tasks in the two conditions indicated no significant difference $[F(1,38)=1.53, p=.22]$.

Rounding and overestimation. The 40 participants supplied a total of 160 time allocations, the majority (73\%) of which were rounded close approximations (e.g., multiples of $5 \mathrm{~min}$ ), with $51 \%$ of all time allocations being either 5 or $10 \mathrm{~min}$. This is also shown in the modal time allocations shown in Table 1. Table 1 also shows the proportion of participants who overestimated. The three tasks (letter delivery, river conditions, and document ordering) with the shortest average actual durations (around 3 to $4 \mathrm{~min}$ ) had the highest proportions of participants providing overestimates $(100 \%, 90 \%$, and $95 \%$, respectively). Conversely, the two tasks with the longest average actual duration (proofreading and balancing bills) of around $7 \mathrm{~min}$ had the lowest proportions of participants providing overestimates ( $60 \%$ and $45 \%$, respectively). In these two tasks, participants who used rounded close approximations had a choice between allocating 5 min (an underestimation) or $10 \mathrm{~min}$ (an overestimation). The modal estimates for these two tasks indicate that the participants tended to give a 5-min time allocation, a choice that is reflected in the proportion of over- and underestimation for these two tasks.

Task segmentation and time allocation. The mean, median, and mode allocated time for the tasks that were scheduled as a group, and for the summed allocated time for the tasks scheduled separately, are shown in Table 1. Comparison of these medians indicates that less time was allocated when the tasks were scheduled as a group. This is further indicated by the mean signed errors. For exam-

Table 1

Summary of Actual Task Duration and Allocated Task Time (in Minutes) for Experiment 1

\begin{tabular}{|c|c|c|c|c|c|c|c|c|c|}
\hline \multirow[b]{2}{*}{ Task } & \multicolumn{2}{|c|}{$\begin{array}{c}\text { Actual } \\
\text { Time to } \\
\text { Complete }\end{array}$} & \multicolumn{2}{|c|}{$\begin{array}{l}\text { Allocated } \\
\text { Time }\end{array}$} & \multirow{2}{*}{$\begin{array}{l}\text { Median } \\
\text { Allocated } \\
\text { Time }\end{array}$} & \multirow{2}{*}{$\begin{array}{c}\text { Mode } \\
\text { Allocated } \\
\text { Time }\end{array}$} & \multirow{2}{*}{$\begin{array}{c}\text { Mean } \\
\text { Signed } \\
\text { Error }\end{array}$} & \multirow{2}{*}{$\begin{array}{c}\text { Mean } \\
\text { Absolute } \\
\text { Error }\end{array}$} & \multirow{2}{*}{$\begin{array}{c}\% \text { Who } \\
\text { Overestimated }\end{array}$} \\
\hline & $M$ & $S D$ & $M$ & $S D$ & & & & & \\
\hline $\begin{array}{l}\text { Scheduled as group: Balance sheet, candy bar, } \\
\text { and order documents }\end{array}$ & 12.8 & 2.2 & 17.9 & 7.3 & 15.0 & 15.0 & +5.1 & 5.0 & 45 \\
\hline $\begin{array}{l}\text { Scheduled separately: Summed balance sheet, } \\
\text { candy bar, and order documents }\end{array}$ & 12.1 & 2.5 & 22.1 & 14.0 & 19.5 & 20.0 & +10 & 8.5 & - \\
\hline $\begin{array}{l}\text { Scheduled as group: Proofreading, deliver let- } \\
\text { ters, and river reports }\end{array}$ & 14.5 & 3.0 & 16.1 & 6.0 & 15.0 & * & +1.5 & 4.0 & 55 \\
\hline $\begin{array}{l}\text { Scheduled separately: Summed proofreading, } \\
\text { deliver letters, and river reports }\end{array}$ & 15.1 & 1.7 & 24.1 & 8.2 & 24.0 & 35.0 & +8.9 & 9.4 & - \\
\hline Proofreading & 7.0 & 1.6 & 8.3 & 4.9 & 6.5 & 5.0 & +1.3 & 3.3 & 60 \\
\hline Deliver letters & 4.2 & 1.2 & 6.7 & 2.2 & 6.0 & 5.0 & +2.5 & 2.4 & 100 \\
\hline River reports & 3.9 & 1.1 & 9.1 & 4.7 & 9.0 & $*$ & +5.2 & 5.5 & 90 \\
\hline Balance sheet & 7.0 & 2.4 & 8.0 & 6.4 & 5.0 & 5.0 & +0.83 & 4.2 & 45 \\
\hline Candy bar & 4.7 & 1.0 & 7.5 & 4.8 & 5.5 & 5.0 & +2.7 & 3.5 & 75 \\
\hline Order documents & 3.1 & 0.9 & 6.5 & 4.2 & 5.0 & 5.0 & +3.4 & 3.5 & 95 \\
\hline
\end{tabular}

${ }^{*}$ Multiple modes evident in data. 
ple, the mean summed signed error for the three tasks allocated time separately was +8.9 min, whereas the mean signed error for the same three tasks allocated time as a group of tasks was $+1.5 \mathrm{~min}$. Between-conditions comparison of allocated time for the proofreading, letter writing, and river report tasks indicated a significant difference $\left[F(1,39)=12.273, p<.001 ; \eta^{2}=.244\right]$. However, the between-conditions comparison of allocated time for the balance sheet, candy bar, and document editing tasks indicated no significant difference $[F(1,38)=1.394$, n.s.]. Inspection of Table 1 indicates that allocated time was larger when each subtask was allocated time separately (summed single task-time allocations), in comparison with the time allocation for the entire clustered task. These results at least partially support our prediction that allocating time to separate (short) tasks results in more time being allocated to them.

Time allocation accuracy. Although we did not predict that task segmentation would increase time allocation accuracy, rather that it would increase the allocated time, it is important to consider the accuracy implications of task segmentation. The mean signed errors (the time allocation minus actual duration) and the mean absolute errors shown in Table 1 indicate that, for the short tasks used in this experiment, segmentation inflated allocated time beyond that which was actually required for task completion. In other words, segmentation increased time allocation error. However, an overallocation of time is perhaps less problematic (and avoids planning fallacy bias) than an underestimation, because the probability of completing the task in the available time is greatly increased, and the individual can begin some other task if he/she finishes early.

\section{EXPERIMENT 2}

In Experiment 2, we attempted to replicate the findings from Experiment 1 by assessing the effect of task segmentation and the influence of using rounded close approximations when actual task time was substantially longer (i.e., 20-40 min). Although the results from Experiment 1 were generally consistent with the prediction that task segmentation would increase allocated time, this had the effect of increasing allocated time beyond that which was required. It is possible that planning-fallacy-type errors (underestimation) are more likely with longer tasks, and for these tasks segmentation may not only increase allocated time, but also improve time allocation accuracy. The experimental design was the same as that used in Experiment 1, except that different tasks, which took longer to complete, were used. The following predictions were made: that participants would tend to provide time allocations that were rounded close approximations (e.g., 5-min "chunks"), and that allocating time for subtasks would result in significantly more time being allocated to them overall (summed subtask time allocations) in comparison with when a single time allocation was given for the entire group of tasks.

\section{Method}

Participants. Forty participants, 19 male and 21 female students, with a mean age of 22.4 years, participated in the experiment (none had participated in Experiment 1). Participants were remunerated for taking part and were debriefed at the end of the experiment.

Materials. Time allocations were made on a plain A4 sheet of paper.

Tasks. Two criteria were used in the design of tasks. As with Experiment 1 , a balance was sought between creating an office environment and having tasks that all participants would find somewhat familiar. Second, individual tasks were designed to have a significantly longer average completion time (between 20 and $40 \mathrm{~min}$ ) than those in Experiment 1. This was achieved by increasing the magnitude of three of the tasks used in Experiment 1 and by designing three new tasks. The six tasks are shown in Appendix B.

Procedure. Participants were assigned randomly to one of two conditions. In the first condition, Tasks 1-3 were allocated time separately and Tasks 4-6 were grouped together and allocated time as a task set. In Condition 2, Tasks 1-3 were grouped together and allocated time as a task set, and Tasks 4-6 were allocated time as separate tasks.

Participants were seated individually at a table; given the experimental instructions (identical to those in Experiment 1), taskactivity descriptions, a time-allocation sheet, folders containing the task materials, a telephone directory, and a "Completed Task" tray; and directed to read the instructions. Participants scheduled the completion of the tasks and completed the tasks in the order that they had chosen. A researcher discretely recorded the time taken for the participant to complete each task.

\section{Results and Discussion}

Table 2 shows the mean actual duration; mean, median, and modal allocated time; and mean signed error (allocated time minus actual duration) for each task. Consistent with Experiment 1, most of the mean signed errors for the six tasks were positive. The exceptions were the proofreading and contact detail look-up tasks, which were allocated less time than was required for their completion. Inspection of the median and modal time allocations for these tasks indicates that these under-allocations are the result of the nature of the time-allocation rounding used for them. Table 2 also shows the proportion of participants who overestimated completion durations; these are generally smaller than those obtained in Experiment 1. Comparison of the overall actual time that the groups required in order to complete the experimental tasks indicated no significant difference $[F(1,38)=2.91, p=.10]$.

Rounding and overestimation. Examination of the allocated times indicated that $83 \%$ of the participants gave values of $10,15,30,40,45,50,60$, or $90 \mathrm{~min}$, which might be considered rounded close approximations. This tendency is reflected also in the median and modal allocated times shown in Table 2.

Task segmentation and allocated time. Table 2 shows the mean and median allocated times for the tasks that were scheduled as a group and for the three tasks scheduled separately. Between-conditions comparison of allocated time for the balance sheet, order documents, and library tasks indicated a significant difference $[F(1,39)=14.503$, $\left.p<.001 ; \eta^{2}=.276\right]$. Similarly, the between-conditions comparison of allocated time for the proofreading, written report, and contacts tasks indicated a significant difference $\left[F(1,39)=5.443, p<.05 ; \eta^{2}=.125\right]$. Inspection of Table 2 indicates that allocated time for both sets of tasks was significantly larger when each subtask was allocated time separately, in comparison with a single time allocation for the relevant task cluster. 
Table 2

Summary of Actual Task Duration and Allocated Task Times (in Minutes) in Experiment 2

\begin{tabular}{|c|c|c|c|c|c|c|c|c|c|}
\hline \multirow[b]{2}{*}{ Task } & \multicolumn{2}{|c|}{$\begin{array}{l}\text { Actual Time } \\
\text { to Complete } \\
\end{array}$} & \multicolumn{2}{|c|}{$\begin{array}{l}\text { Allocated } \\
\text { Time }\end{array}$} & \multirow{2}{*}{$\begin{array}{l}\text { Median } \\
\text { Allocated } \\
\text { Time } \\
\end{array}$} & \multirow{2}{*}{$\begin{array}{l}\text { Mode } \\
\text { Allocated } \\
\text { Time }\end{array}$} & \multirow{2}{*}{$\begin{array}{l}\text { Mean } \\
\text { Signed } \\
\text { Error }\end{array}$} & \multirow{2}{*}{$\begin{array}{l}\text { Mean } \\
\text { Absolute } \\
\text { Error }\end{array}$} & \multirow{2}{*}{$\begin{array}{c}\% \text { Who } \\
\text { Overestimatec }\end{array}$} \\
\hline & $M$ & $S D$ & $M$ & $S D$ & & & & & \\
\hline $\begin{array}{l}\text { Scheduled as group: Balance sheet, order } \\
\text { documents, and library subscription details }\end{array}$ & 71.6 & 10.1 & 59.0 & 22.4 & 60.0 & 60.0 & -12.6 & 20.7 & 20 \\
\hline $\begin{array}{l}\text { Scheduled separately: Summed balance } \\
\text { sheet, order documents, and library sub- } \\
\text { scription details }\end{array}$ & 76.6 & 15.2 & 84.7 & 20.1 & 85.0 & 70.0 & +8.05 & 21.7 & - \\
\hline $\begin{array}{l}\text { Scheduled as group: Proofreading, written } \\
\text { report, and contact detail look-up }\end{array}$ & 85.5 & 16.4 & 59.6 & 21.2 & 60.0 & 60.0 & -25.9 & 27.8 & 5 \\
\hline $\begin{array}{l}\text { Scheduled separately: Summed proofreading, } \\
\text { written report, and contact detail look-up }\end{array}$ & 77.5 & 14.3 & 77.3 & 26.3 & 72.5 & 65.0 & +0.25 & 20.4 & - \\
\hline Proofreading & 24.5 & 9.2 & 23.7 & 9.9 & 20.0 & 20.0 & -0.78 & 8.1 & 50 \\
\hline Written report & 22.3 & 5.0 & 28.2 & 14.0 & 30.0 & 30.0 & +5.9 & 10.3 & 60 \\
\hline Contact detail look-up & 30.6 & 7.1 & 25.3 & 11.3 & 30.0 & 30.0 & -5.3 & 10.6 & 40 \\
\hline Balance sheet & 22.2 & 10.3 & 22.6 & 9.8 & 20.0 & 20.0 & +0.4 & 9.7 & 50 \\
\hline Order documents & 18.7 & 3.1 & 25.8 & 10.3 & 20.0 & 20.0 & +7.1 & 8.7 & 80 \\
\hline Library subscription details & 35.7 & 6.9 & 36.2 & 9.4 & 35.0 & 30.0 & +0.55 & 9.0 & 60 \\
\hline
\end{tabular}

Time allocation accuracy. The signed errors shown in Table 2 indicate that for the longer tasks used in Experiment 2, segmentation inflated allocated time to approximately that which was required for task completion (or slightly more in the case of the balance sheet, order documents, and library subscription tasks). Another way to consider this is that the mean signed errors for the time allocation made under the grouped task condition indicate gross underestimation (evidence of a planning fallacy bias) of the required time. The mean absolute errors shown in Table 2 indicate that the extent of underestimation produced under the grouped task condition was about the same as the extent of overestimation produced in the task segmentation condition.

\section{EXPERIMENT 3}

In Experiments 1 and 2, participants made numerical estimates of allocated task time. The results clearly showed extensive use of rounded close approximations, as well as a main effect of task segmentation on allocated time. In Experiment 3 , we provided participants with a timeline that was stated as representing $1 \mathrm{~h}$. Allocated time for both subtasks and grouped tasks was indicated by placing a mark on the timeline. This response method made it more difficult for participants to use rounded close approximations. The primary objective of the experiment was to determine whether the task segmentation effect observed in Experiments 1 and 2 would be found when the use of rounded close approximations was more difficult. Given that task segmentation had no significant effect on actual task times and that understanding the mechanisms behind the task segmentation effect does not necessarily require an examination of time allocation accuracy, participants did not actually complete the tasks in Experiment 3. We also changed the tasks for Experiment 3. In Experiments 1 and 2, none of the tasks were linked by a common objective. Arguably, the task-segmentation principles suggested in the time-management literature are intended to apply to a sequence of tasks aimed at a common goal. Thus, in this experiment we designed two principal tasks, each with three clearly related subtasks.

\section{Method}

Participants and Design. Two tasks (document editing and bill paying), each with three subtasks, were developed for the experiment. Ninety-nine participants (summer school students) were asked to give four time allocations: one for a complete task and three for subtasks. Participants were assigned randomly to one of two groups. Fifty participants (22 males with a mean age of 29.4, and 28 females with a mean age of 30.2) gave a time allocation for the complete document editing task and for the three bill paying subtasks. The remaining 49 participants ( 13 males with a mean age of 30.3 , and 36 females with a mean age of 27.8) gave a time allocation for the complete bill paying task and for the three document editing subtasks. None of the participants had served in either Experiment 1 or 2.

Materials. A time line (measuring $110 \mathrm{~mm}$ ) was provided under each task description (five different orders of task descriptions were used). The left end was labeled "0" and the right end was labeled "60." Participants were asked to "Please indicate how long you would allocate to the completion of each task by placing a mark on the line." Participants' responses were converted from a mark on the timeline to a measure in minutes by multiplying the marked line length by .545 .

Tasks. Two tasks were developed, each presented as either a complete task cluster or as three separate tasks. The task descriptions are shown in Appendix C. Two dashed lines (which did not appear in the experimental versions) show the subtask breaks within each complete task cluster. Words in italics were inserted into the subtasks' descriptions so that they were understandable as task descriptions.

Procedure. Participants completed their experimental questionnaire individually. Participants were remunerated for taking part and were debriefed at the end of experiment.

\section{Results}

The mean times in minutes for the time allocations for the complete tasks were, for bill paying, $29.9(S D=12.9)$, and for document editing, $33.6(S D=15.8)$. In contrast, the mean times in minutes for the time allocations for the summed subtasks were, for bill paying, $52.0(S D=28.6)$, and for document editing, $50.8(S D=25.3)$. Betweengroups comparison of allocated time for the bill paying task indicated a significant difference $[F(1,98)=24.359$, $\left.p<.001 ; \eta^{2}=.201\right]$. Similarly, the between-groups comparison of allocated time for the document editing task indicated a significant difference $[F(1,98)=16.468, p<$ $\left..001 ; \eta^{2}=.145\right]$. In conjunction with the means, these results indicate that allocated time for both the bill paying 
and the document editing tasks was significantly larger when each subtask was allocated time separately, in comparison with a single time allocation for the complete task. These results suggest that the task segmentation effect still occurs when the use of rounded close approximations is made more difficult and when the segmented tasks are all related to one overall objective.

\section{GENERAL DISCUSSION}

The planning fallacy is a well-documented bias in which required task duration is underestimated, and it can result in negative effects on individuals' task time allocation outcomes. The segmentation effect appears to be one way by which allocated task time can be increased significantly, and thus may be one approach to reducing the possibility of planning fallacy bias. Experiment 2 in particular showed that summed subtask time allocations were very close to the actual time required for task completion, whereas a single time allocation for the complete task tended to produce marked underestimation (planning fallacy bias). The segmentation effect also appears to occur when the tasks are rather unrelated (as in Experiments 1 and 2) and when the tasks are more behaviorally linked to a single overall objective (as in Experiment 3).

The segmentation effect, despite producing consistently larger time allocations, appears to have an interesting relationship with time-allocation accuracy. Inflating allocated time beyond that required for task completion is, in an objective sense, an error-producing effect. But at a functional level, overestimation errors are probably more advantageous than underestimation errors (or planning fallacy bias). At least with the overallocation of time, tasks are more likely to get completed, and the unused time can always be used for some other task. Furthermore, the segmentation effect may be more useful as actual task duration increases. The results from Experiment 1, which used very short tasks, are not as favorable as those from Experiment 2, which used longer ones, if a purely functional evaluation is applied.

Time-management models (Macan, 1994) typically have recommended breaking projects into subcomponents (task segmentation) and then developing priorities for each and allocating time to each. Interestingly, there appears to have been little empirical evidence to support the value of tasktime allocation at the subtask, as opposed to the wholetask, level. Although an extensive literature shows that individuals overestimate the duration of short stimuli and underestimate the duration of long stimuli (Eisler, 1976), this research does not appear to have been used directly to support specific time-management principles. The research on unpacking by Kruger and Evans (2004) was able to show that unpacking a task before giving a time allocation for the whole task increased the time allocation when compared with a packed condition. However, unpacking only, with no subtask time allocation, is not what time-management models prescribe. Still, unpacking was shown to reduce planning fallacy bias. It would be interesting to compare time allocations made under unpacking instructions with those made under segmentation and individual subtask time-allocation instructions. Presently it is not clear how unpacking inflates allocated time. Does it lead to an allocation based on a mental summing process, where time is allocated to the unpacked subtasks and then summed?

A major difference between our research and the unpacking studies of Kruger and Evans (2004) is that our experimental designs created the task segmentation; we did request that the participants engage in unpacking before time allocation. However, neither our research nor that of Kruger and Evans has shown unpacking/segmentation to be a process that occurs under everyday circumstances. To be sure, time-management models suggest that individuals should perform unpacking and segmentation. But are these processes preferred routinely, or do individuals prefer to deal with large units of work and thus large units of time that seem prone to planning fallacy bias? Individuals do seem to unpack experiences when encoding them in memory, as shown by work on script formation (Schank \& Abelson, 1977). Furthermore, a fundamental feature of script formation is that they allow the nature of future experiences to be anticipated. However, it may be that our knowledge of the subcomponents of experiences is not used routinely for decision-making tasks.

The literature on decomposition in decision making has found results that are consistent with our segmentation effect; for example, a single estimate relating to a population (e.g., school dropout rate) is sometimes less accurate than a set of mathematically combined estimates relating to the population's subcomponents (see Armstrong, Denniston, \& Gordon, 1975; Henrion, Fischer, \& Mullin, 1993; Hora, Dodd, \& Hora, 1993; MacGregor \& Armstrong, 1994). However, although it appears that decomposition can have positive effects (e.g., increasing accuracy) in decision making, it is not a process that characterizes everyday decision making (Berkeley \& Humphreys, 1982). Thus, the use of task segmentation and time allocation to subtasks might reduce planning fallacy bias, but, like decomposition, it is probably cognitively demanding and is not how individuals normally deal with their task time-allocation needs.

\section{AUTHOR NOTE}

D.K.F. is now at the Department of Management and International Business, Massey University, New Zealand. The authors thank Richard Block and two anonymous reviewers for helpful comments on an earlier draft of the manuscript. Correspondence concerning this article should be addressed to C. D. B. Burt, Department of Psychology, University of Canterbury, Private Bag 4800, Christchurch, New Zealand (e-mail: christopher.burt@canterbury.ac.nz).

\section{REFERENCES}

Armstrong, J. S., Denniston, W. B., \& Gordon, M. M. (1975). The use of the decomposition principle in making judgments. Organizational Behavior \& Human Decision Processes, 14, 257-263.

Berkeley, D., \& Humphreys, P. (1982). Structuring decision problems and the "bias heuristic." Acta Psychologica, 50, 201-252.

Block, R. A., \& ZAKAY, D. (1997). Prospective and retrospective duration judgments: A meta-analytic review. Psychonomic Bulletin \& Review, 4, 184-197.

Buehler, R., Griffin, D., \& MacDonald, H. (1997). The role of motivated reasoning in optimistic time predications. Personality \& Social Psychology Bulletin, 23, 238-247.

Buehler, R., Griffin, D., \& Ross, M. (1994). Exploring the "planning fallacy": Why people underestimate their task completion times. Journal of Personality \& Social Psychology, 67, 366-381. 
Burt, C. D. B., \& Forsyth, D. (1999). Designing materials for efficient time management: Segmentation and planning space. Cognitive Technology, 4, 11-18.

Burt, C. D. B., \& Kemp, S. (1994). Construction of activity duration and time management potential. Applied Cognitive Psychology, 8, 155-168.

Byram, S. J. (1997). Cognitive and motivational factors influencing time prediction. Journal of Experimental Psychology: Applied, 3, 216-239.

Claessens, B. J. C., Van Eerde, W., Rutte, C. G., \& Roe, R. A. (2004). Planning behavior and perceived control of time at work. Journal of Organizational Behavior, 25, 937-950.

EISLER, H. (1976). Experiments on subjective duration 1868-1975: A collection of power function exponents. Psychological Bulletin, 83, 1154-1171.

Francis-Smythe, J. A., \& Robertson, I. T. (1999). On the relationship between time management and time estimation. British Journal of Psychology, 90, 333-347.

Grimstad, S., Jørgensen, M., \& MoløKken-Østvold, K. (2006). Software effort estimation terminology: The tower of Babel. Information \& Software Technology, 48, 302-310.

Henrion, M., Fischer, G. W., \& Mullin, T. (1993). Divide and conquer? Effects of decomposition on the accuracy and calibration of subjective probability distributions. Organizational Behavior \& Human Decision Processes, 55, 207-227.

Hora, S. C., Dodd, N. G., \& Hora, J. A. (1993). The use of decomposition in probability assessment of continuous variables. Journal of Behavioral Decision Making, 6, 133-147.

HorNIK, J. (1981). Time cue and time perception effect on response to mail survey. Journal of Marketing Research, 18, 243-248.

Huttenlocher, J., Hedges, L. V., \& Bradburn, N. M. (1990). Reports of elapsed time: Bounding and rounding processes in estimation.
Journal of Experimental Psychology: Learning, Memory, \& Cognition, 16, 196-213.

JøRGENSEN, M. (2004). Top-down and bottom-up estimation of software development effort. Information \& Software Technology, 46, 3-16.

KAHNEMAN, D., \& TVERSKY, A. (1979). Intuitive prediction: Biases and corrective procedures. TIMS Studies in Management Science, 12, 313-327.

Kruger, J., \& Evans, M. (2004). If you don't want to be late, enumerate: Unpacking reduces the planning fallacy. Journal of Experimental Social Psychology, 40, 586-598.

Macan, T. M. (1994). Time management: Test of a process model. Journal of Applied Psychology, 79, 381-391.

MacGregor, D. G., \& Armstrong, J. S. (1994). Judgmental decomposition: When does it work? International Journal of Forecasting, 10, 495-506.

Newby-Clark, I. R., Ross, M., Buehler, R., Koehler, D. J., \& GRIFFIN, D. (2000). People focus on optimistic scenarios and disregard pessimistic scenarios while predicting task completion times. Journal of Experimental Psychology: Applied, 6, 171-182.

Oden, G. (1987). Concept, knowledge, and thought. Annual Review of Psychology, 38, 203-227.

Roy, M. M., Christenfeld, N. J. S., \& McKenzie, C. R. M. (2005). Underestimating the duration of future events: Memory incorrectly used or memory bias? Psychological Bulletin, 131, 738-756.

Schank, R. C., \& Abelson, R. P. (1977). Scripts, plans, goals, and understanding: An inquiry into human knowledge structures. Hillsdale, NJ: Erlbaum.

Smith, E. E., \& Medin, D. L. (1981). Categories and concepts. Cambridge, MA: Harvard University Press.

ZAKAY, D. (1990). The evasive art of subjective time measurement: Some methodological dilemmas. In R. A. Block (Ed.), Cognitive models of psychological time (pp. 59-84). Hillsdale, NJ: Erlbaum.

\section{APPENDIXA \\ Tasks for Experiment 1}

\section{Task 1}

A three-page document, typed (double spaced) on A4 paper is provided. Your task is to proof read it for spelling mistakes. Circle each spelling mistake that you find.

\section{Task 2}

Deliver eight letters to their respective pigeonholes. The addressee's pigeonholes are located in Room 209 of the psychology building (i.e., the Resource room). This room is two floors directly below your present location (opposite the secretaries' office).

\section{Task 3}

Obtain the current river conditions (water colour \& fish-ability) for the following four Canterbury rivers: Waimakariri river, Rakaia river, Hurunui river, and Waiau river. To obtain this information you will need to phone Fish and Game North Canterbury's automated river report. The phone number should be looked up in the telephone book provided.

\section{Task 4}

Five 'bills' (e.g., power bill, phone bill) are provided, along with an account balance sheet. Your task is to enter the 'billed amount' in the debt column and subtract the amount from the balance, creating a new balance after each subtraction (pen and paper subtraction-no calculator).

\section{Task 5}

Buy a candy bar (or similar) from the vending machine just inside the law café (if you look out the window you will see the new law building - the café is located near the main entrance on the ground floor). One dollar is in the appropriate folder.

\section{Task 6}

Arrange 20 job applications in alphabetic order with respect to the applicants' surnames (i.e., 'A' in the front, through to ' $\mathrm{Z}$ ' at the back). 
APPENDIX B

Tasks for Experiment 2

Task 1

A 13-page company report, typed (double spaced) on A4 paper is provided. Your task is to proofread it for spelling mistakes. Circle each spelling mistake that you find.

\section{Task 2}

The consumer research company you work for is currently interested in how people spend their holiday time. As part of this information gathering process you are required to write a two-page document describing what you did during the Christmas holidays.

\section{Task 3}

The company you work for is thinking of building or renting a new office. As part of this process they want to get quotes from relevant providers. Using the telephone book (yellow pages) provided look-up and record the names and phone numbers (response forms provided) of 10 Builders, Plumbers, Real Estate Agents, Concrete contractors, Civil Engineers, Interior Decorators, Roofing Contractors and Architects.

\section{Task 4}

Twenty 'bills' (e.g., power bill, phone bill) are provided, along with an account balance sheet. Your task is to enter the 'billed amount' in the debt column and subtract the amount from the balance, creating a new balance after each subtraction (pen and paper subtraction-no calculator).

\section{Task 5}

The company you work for has many job application letters, which it has received over the past five years. These need to be ordered and filed. The folder contains 100 job application letters. First, you need to sort the letters with respect to the year they were sent. This will result in five groups of letters. For each of these five groups you are required to arrange the job applications in alphabetic order with respect to the applicant's surname (i.e., 'A' in the front, through to ' $Z$ ' at the back). The paper clips provided should be used to keep each group together.

\section{Task 6}

The company you work for is thinking of subscribing to various academic journals. Your task is to gather subscription information on these journals (normally found on the inside front or back cover). Go to the current periodicals section of the main library and record the annual institutional subscription rate (non-airmail where applicable) and the subscription address for the following 10 journals (titles and call numbers were provided).

\section{APPENDIX C \\ Tasks for Experiment 3}

\section{Document Editing Task}

Assume you are working in an office. A three-page document, typed (double spaced) on A4 paper is provided. Your task is to proof read it for spelling mistakes. Circle each spelling mistake that you find.--Assume you find 25 spelling mistakes (in a 3 page document. Your task is to open) and now open the document (in Word) and correct all 25 mistakes.--Finally, you (Your task is to) print the (a 3 page) document (the printer is next to the computer), and ring-bind the document with a ring-binder which is also in the office.

\section{Bill Paying Task}

Assume you arrive home after a 3 week overseas holiday. Waiting for you are 7 letters - 'bills' (i.e., power bill, phone bill, magazine subscription, Visa bill, vet bill, hire-purchase bill, and garage bill) - which you open and read.--Assume you pay all your bills by cheque, and you proceed (Your task is) to write a cheque for each of the 7 bills (i.e., power bill, phone bill, magazine subscription, Visa bill, vet bill, hire-purchase bill, and garage bill).--Finally, you (Assume you wish to post 7 bills (i.e., power bill, phone bill, magazine subscription, Visa bill, vet bill, hire-purchase bill, and garage bill) which you have previously written a cheque for. Your current task is to) address an envelope for each of the 7 bills, place the invoice and cheque inside, seal and affix a stamp ready for posting.

(Manuscript received September 21, 2006;

revision accepted for publication November 5, 2007.) 